$\mathcal{G S}_{\text {https://doi.org/10.3765/sp.12.2 }}^{\text {Semantics \& Pragmatics Volume 12, Article 2, } 2019}$

This is an EARLY ACCESS version of

Mackay, John. 2019. Modal interpretation of tense in subjunctive conditionals.

Semantics and Pragmatics 12(2). 1-29. https://doi.org/10.3765/sp.12.2.

This version will be replaced with the final typeset version in due course.

Note that page numbers will change, so cite with caution. 
EARLY ACCESS

\title{
Modal interpretation of tense in subjunctive conditionals
}

\author{
John Mackay
}

\begin{abstract}
The paper gives an account of the meaning of subjunctive conditionals according to which the past tense receives a modal interpretation. The view allows the worlds of the antecedent to include the world of the context of utterance, and thus it avoids a problem pointed out by Mackay (2015) for previous modal views of the past tense in subjunctive conditionals. I argue that it also explains a variety of facts about the relationship among subjunctive morphology, counterfactuality, and presupposition.
\end{abstract}

Keywords: conditionals, counterfactuals, tense, subjunctive, past

\section{Introduction}

The conditionals traditionally labelled "subjunctive" contain a layer of past tense morphology beyond what one would expect from their temporal interpretation. This morphology is absent from the conditionals traditionally labelled "indicative".

(1) If it is raining now, the sidewalks are wet.

(2) If it were raining now, the sidewalks would be wet.

In this pair, both conditionals pertain to the present, as indicated by the presence of "now". Yet in the subjunctive, (2), both the antecedent and the consequent take a morphologically past tense form: "were" or "would" (the latter being the past tense of "will"). ${ }^{1}$

In the following pair, meanwhile, both conditionals pertain to a past event.

(3) If Oswald didn't shoot Kennedy, someone else did.

(4) If Oswald hadn't shot Kennedy, someone else would have.

Yet while the indicative conditional (3) is in the simple past, the subjunctive version, (4), takes a pluperfect form. Ordinarily, outside conditionals, the pluperfect is used

1 This point is independent of the difference in register between English speakers who retain the more formal subjunctive "if it were raining" and those who use "if it was raining". Both of these are past tense forms; "if it were" is a past subjunctive to be contrasted with the now-obsolete present subjunctive "if it be". 
when the event described by the sentence precedes not only the present but also some intervening past time. The conditional (4) does not in any obvious sense share this pluperfect meaning; it is simply the form used to make counterfactual claims about the past. This pattern (with some differences in the details of tense and aspect) is widespread across historically unrelated natural languages; an array of empirical research to this effect is presented by Iatridou (2000). ${ }^{2}$ This suggests that the tense in the subjunctive conditional plays some semantic role and is not an accidental homophony.

This observation raises a puzzle. The difference between indicative and subjunctive conditionals does not immediately appear to concern the time of the events or states involved. Both indicative and subjunctive conditionals can pertain to the past, present, or future. Rather, the difference between the forms pertains to the conditional's relationship to the presuppositions of the context. As observed by Stalnaker (1975), an indicative conditional is assertable only if the antecedent is consistent with the common ground. Equivalently, if a conditional's antecedent is presupposed to be false, the conditional is assertable only in the subjunctive. By contrast, it is not true that a conditional is assertable in the subjunctive only if its antecedent is presupposed to be false. In certain contexts, subjunctive conditionals can have true antecedents, and the world of the context of utterance can be among the worlds of the antecedent at which the consequent is evaluated. This asymmetry in the relationship between counterfactuality and the subjunctive form is disanalogous to the relationship between past times and past tense. There are subjunctives whose antecedents are not presupposed to be counterfactual, and for which the actual world is among the selected antecedent worlds. By contrast, the past tense, in its standard temporal interpretation, does not merely convey that the event or state described may optionally precede the speech time; it conveys (leaving aside sequence of tense phenomena) that it does precede the speech time. For this reason, subjunctives with true antecedents raise difficulties in accounting for the role of tense in conditionals.

Accounts of these phenomena can be divided into two broad kinds. One type of theory, categorized by Schulz (2014) as "past-as-past", maintains that the past tense is interpreted here in the standard temporal way, and thus that the difference between the conditionals is temporal after all. Of course, subjunctive conditionals are not just about past times; these views accommodate this point by proposing that the past tense takes wide scope, so the subjunctive conditional expresses the claim that some other conditional was true at a time before the time of utterance. Typically, in such

2 Iatridou observes that it occurs throughout Indo-European languages, and it has also been observed, for example, in Papago (Hale (1969)),Proto-Uto-Aztecan (Steele (1975)), Korean (Han (1996)), Hebrew, Turkish, Basque, and others (James (1982), Fleischman (1989)). Overall, though I will continue to use them, the labels "subjunctive" and "indicative" are misleading, since they do not capture the distinctions in tense and aspect that are involved. 
views, subjunctive conditionals take a historical modal base, according to which a world is accessible at a time if it shares its history up to that time with the world of evaluation. Advocates of this type of view include Ippolito (2013), Arregui (2009), Romero (2014) and Khoo (2015); earlier versions are given by Dudman (1984) and Crouch (1994).

Another type of view, which Schulz labels "past-as-modal", proposes that the past tense in subjunctive conditionals has a modal interpretation that shares an abstract structural property with the temporal interpretation. In its temporal interpretation, the past tense interacts with a structure consisting of a set of times $T$, a dedicated present time $t^{*}$, and a relation < of precedence between times. When a clause is in the past tense, the past tense expresses that the time of the event or state in question precedes the time of the context of utterance. In a past-as-modal view, we construe the meaning of the past tense at a higher level of abstraction, affecting structures consisting of a set of indices $I$, a relation $<$ on $I$, and a designated index $i^{*}$. The past tense expresses of some contextually salient index that it bears the relation $<$ to the designated index $i^{*}$. These indices can be times, but they can also be some modal entities (worlds or sets thereof). The subjunctive form of the conditional contains the modally interpreted past tense, and thus indicates that the modal entities in question bear the relation $<$ to the designated index $i^{*}$. Iatridou (2000) and Schulz (2014) give versions of this view. Though they differ in various points, these past-as-modal views are arguably closer in spirit to the older views of Stalnaker (1975) and Kratzer (1981) than are the past-as-past views, in the sense that they maintain that the basic difference does not have to do with the time of evaluation involved. ${ }^{3}$

The central question for the advocate of the past-as-modal view is what the modal versions of $I,<$, and $i^{*}$ are. This question is not straightforward, and as pointed out by Mackay (2015), there is a problem with existing past-as-modal views that concerns whether the world of utterance may be among the selected worlds of the antecedent. This means that we do not currently have a past-as-modal view that assigns conditionals truth conditions that correctly capture the difference in meaning between the two forms.

My goal in this paper is to advance a past-as-modal view that rightly predicts how subjunctive antecedents relate to the world of utterance while maintaining the right overall relationship between subjunctive morphology and counterfactuality. I state the view in Section 2. In subsequent sections, I motivate it and examine its consequences by way of comparison with a number of earlier views.

I do not argue in this paper against the views mentioned above in which the past tense always receives a temporal interpretation; the viability of tense-as-tense

3 Starr (2014), meanwhile, also has a broadly past-as-modal view, but he also argues that a satisfactory compositional treatment of tense in subjunctive conditionals requires giving up static truth conditions in favor of a dynamic semantics, and so his view does not exactly fit the structure just described. 
views deserves a separate treatment, and various issues concerning these views are discussed in the references cited above.

\section{The view}

\subsection{Preliminaries}

A past-as-modal view, as we shall understand it, maintains that the past tense has a modal interpretation in which it interacts with structures consisting of a set of indices $I$, a relation < on $I$, and a designated index $i^{*}$, expressing of some contextually salient index $i$ that it bears the relation $<$ to the designated index $i^{*}$. My view will be a version of this framework, with a specific proposal for what $I,<$ and $i^{*}$ are in the modal case.

I follow Heim (1994) in construing tenses as presuppositions about the value of a contextually specified parameter. ${ }^{4}$ More specifically, Heim treats tense as a presupposition about the value of a variable that ranges over times. Thus, where $S$ is a clause in the scope of the past containing some variable $i$ on which the past operates, the past carries the following presupposition.

$\operatorname{PAST}\left(S_{i}\right)$ presupposes in a context that the value of $i$ supplied by the contextually given assignment bears the relation $<$ to the designated index $i^{*}$.

Of course, it remains to specify what $<$ and $i^{*}$ are in the modal case.

I present the view in a framework along the lines of Kratzer (1981), in which conditionals are formed from the restriction by an if-clause of a modal which is sensitive to a modal base and ordering source. In order to harmonize Kratzer's framework with Heim's presuppositional account of tense, I adopt the idea from von Fintel \& Heim (2002) that the modal base and ordering source are represented by variables whose value is supplied by a contextual assignment. The values of these variables are functions from worlds to sets of propositions. Kratzer uses $g$ for ordering sources, which is also traditional for assignments. To avoid confusion I will designate ordering sources with $o$. An ordering source $o$, given a world $w$, determines an ordering $\leq_{o(w)}$, which is not to be confused with the relation $<$ that is involved in the past's modal meaning. For simplicity's sake, I will assume the Limit Assumption that there is a unique set of nearest $p$-worlds for any possible proposition $p .{ }^{5}$ With

4 This is largely a choice of convenience; to what extent an analogous view could be developed in a Priorian model of tense is an interesting question that deserves further thought.

5 Assuming that every set of worlds corresponds to a proposition, this condition is equivalent to what Kaufmann (2018) calls the powerset limit assumption. Kaufmann shows that this version is, strictly speaking, stronger than what is needed. One could make do with what Kaufmann calls the lower set 
this assumption, we can give truth conditions for the conditional that quantify over the nearest possible worlds, as follows:

$$
\begin{aligned}
& \llbracket \square_{f, o}: \text { if } p, q \rrbracket^{c, w, g}=1 \text { iff for all } w^{\prime} \in \cap \llbracket f \rrbracket^{g}(w) \cap p \text { such that for all } \\
& w^{\prime \prime} \in \cap \llbracket f \rrbracket^{g}(w) \cap p, w^{\prime} \leq \llbracket o \rrbracket^{g}(w) w^{\prime \prime}, \llbracket q \rrbracket^{c, w^{\prime}, g}=1 .
\end{aligned}
$$

I also assume, as is common in both the past-as-past and past-as-modal literatures, that subjunctive conditionals take a wide-scope past tense; they thus have a simplified logical form as follows:

$$
\operatorname{PAST}\left(\square_{f, o}: \text { if } p, q\right)^{6}
$$

\subsection{The meaning of the modal past}

With that, let us then turn to the question of what the indices $I$, the relation $<$, and the designated index $i^{*}$ are in the modal case.

- The past's modal interpretation operates on modal bases-or, more specifically, on the values of modal bases. Thus we take the entities $I$ in the modal case to be sets of propositions, which are the values of modal bases.

- We take the relation $<$, in the modal case, to be the proper subset relation $\subset$.

- The designated index $i^{*}$ we take to be the factive common ground, which is the true subset of the common ground in the sense of Stalnaker (1978).

The common ground, in a context of utterance, is the set of propositions that are presupposed in the context. Presupposition is not a factive attitude; one can presuppose a false proposition. The factive common ground, in a context of utterance, is the set of propositions that are presupposed and true in the context of utterance. Roughly (leaving aside the differences between knowledge and true presupposition) the factive common ground determines the set of worlds that are epistemically possible in a context. The reasons for choosing the factive common ground, rather than the whole common ground, as the designated index will come to the fore below in section 3.2, when the view is contrasted with those of Stalnaker (1975) and von Fintel (1998).

limit assumption, according to which not all sets of worlds have a minimal set, but only all those that are downwardly closed.

6 This formulation, of course, glosses over a number of linguistic details, such as how exactly the temporal morphology on each of the constituents gets interpreted as an expression of the outer past tense. 
There are two ways to think of the intuitive motivation for the proper subset relation as the choice for $<$, one in relation to Stalnaker's view and one in relation to tense. Stalnaker informally characterizes the subjunctive as a device for suspending presuppositions. This way of understanding the $<$ relation captures this idea: the modal past indicates that some of the presuppositions from the factive common ground have been removed from the modal base. By analogy with tense, meanwhile, the intuitive idea is that among information states less informative than our current information, the information states become progressively more remote from speakers' current information state as propositions get removed. Thus, this way of understanding the $<$ relation captures an intuitive notion of remoteness in one direction from the default, just as the temporal version of $<$ captures a notion of remoteness in one direction from the present time. Of course, in the temporal case the $<$ relation is not the subset relation; it is not the case that one time is earlier than another if and only if it is a subset of it. But since worlds or other modal entities do not literally precede each other in the way that times do, we should not expect the relation $<$ to be literally the same in the temporal and modal case.

Putting all these points together, the view is that a subjunctive conditional carries the presupposition that the modal base for the modal restricted by the if-clause determines a proper subset of the factive common ground. In the view of Kratzer (1981), the modal base for subjunctive conditionals is empty. Since the empty set is a proper subset of any nonempty set, my view is consistent with Kratzer's view, but it does not require it. It also allows, though, that some presuppositions are retained in a subjunctive modal base, as suggested by Heim (1992). The relationship between my view and Heim's is discussed further in section 3.4, as is that of Kaufmann (2013), who also proposes that modal bases for subjunctive conditionals are nonempty subsets of some salient set of propositions.

Thus, again, the truth-conditions of conditionals generally are as follows:

$$
\begin{aligned}
& \llbracket \square_{f, o}: \text { if } p, q \rrbracket^{c, w, g}=1 \text { iff for all } w^{\prime} \in \cap \llbracket f \rrbracket^{g}(w) \cap p \text { such that for all } \\
& w^{\prime \prime} \in \cap \llbracket f \rrbracket^{g}(w) \cap p, w^{\prime} \leq \llbracket o \rrbracket^{g}(w) w^{\prime \prime}, \llbracket q \rrbracket^{c, w^{\prime}, g}=1 .
\end{aligned}
$$

A subjunctive conditional is formed by putting the past tense outside the scope of the modal, which expresses the presupposition that the value of the variable for the modal base determines a proper subset of the factive common ground. If we construe presupposition failure as undefinedness (a choice to which I am not deeply theoretically committed, but which is widespread), we obtain the following conditions for cases in which the past operates on a conditional with a modal base variable:

$\llbracket \operatorname{PAST}\left(\square_{f, o}:\right.$ if $\left.p, q\right) \rrbracket^{c, w, g}$ is defined iff $\llbracket f \rrbracket^{g}(w) \subset C^{T}$, where $C^{T}$ is the set of propositions presupposed in $c$ that are true at $w_{c}$. 
If defined, $\llbracket \operatorname{PAST}\left(\square_{f, o}:\right.$ if $\left.p, q\right) \rrbracket^{c, w, g}=1$ iff for all $w^{\prime} \in \cap \llbracket f \rrbracket^{g}(w) \cap p$ such that for all $w^{\prime \prime} \in \cap \llbracket f \rrbracket^{g}(w) \cap p, w^{\prime} \leq \llbracket o \rrbracket^{g}(w) w^{\prime \prime}, \llbracket q \rrbracket^{c, w^{\prime}, g}=1$.

\subsection{Indicative conditionals}

In order to make predictions about how the assertability conditions for indicative and subjunctive conditionals differ, an account of subjunctive conditionals needs to be accompanied by an account of indicative conditionals. The accompanying view of indicative conditionals is that the modal base for indicative conditionals is the factive common ground.

I exclude from the present discussion the "double modal" analyses that have been proposed by many theorists for deontic or practical conditionals. ${ }^{7}$ In these proposals, the antecedent does not restrict the overt modal in the consequent but a tacit modal, usually epistemic, that is posited in the structure in addition to the overt modal. I do not have a theory here of how exactly the tense morphology interacts with the overt and covert modals, and whether indicative or subjunctive surface morphology on such conditionals indicates that the relevant meaning applies to the overt modal, the covert one, or both. The application of the view to conditionals with two modals but just one antecedent will remain a question for future research.

This issue aside, the view is that the modal base for indicative conditionals is the factive common ground. There are two ways of implementing this view, between which I am neutral. The difference depends largely on a syntactic question that deserves a separate treatment.

Subjunctive conditionals are marked by past tense. Do indicative conditionals, analogously, have present tense in the same wide-scope position, with an analogous modal reading? On the surface, it does not appear that indicative conditionals all have present tense. Consider an indicative conditional with a past-tense antecedent and consequent:

$$
\text { If Oswald didn't shoot Kennedy, someone else did. }
$$

There is no obvious sign of present tense here, and one might propose that there is none. One might propose, therefore, that indicative conditionals have a logical form like the following, with no wide-scope tense (leaving aside whatever narrow-scope tenses are on the antecedent and consequent themselves, such as the past tense in (5)):

$$
\left(\square_{f, o}:\right. \text { if p, q) }
$$

7 See, for example, Frank (1996), Zvolenszky (2002), Condoravdi \& Lauer (2016), Kaufmann \& Schwager (2009). 
On the other hand, one might propose that there is a hidden present tense here in the place of the past tense in subjunctive conditionals, obtaining a structure like:

$$
\operatorname{PRES}\left(\square_{f, o}: \text { if } \mathrm{p}, \mathrm{q}\right)
$$

Whether modals appear outside the scope of any tense at all is a somewhat controversial question, and I do not wish to take a stand between these options here. ${ }^{8}$ Thus, I will give an account for each version of the view.

Suppose that there is a wide-scope present tense in indicative conditionals. In this case, we can postulate that the present tense, with its modal interpretation, presupposes that the modal base is the factive common ground. This is structurally parallel to the standard temporal interpretation that the salient event time is the present.

On the other hand, suppose that there is no present tense in at least some indicative conditionals. In this case, the indicative conditional does not carry any presupposition at all about the modal base's relation to the factive common ground. However, with such a view, we nevertheless may be able derive the principle that an indicative conditional should be asserted only when the modal base is the factive common ground, via the principle of Maximize presupposition from Heim (1991). This is the principle that in a context in which two sentences would contribute the same new information to the context but one of the sentences carries a stronger presupposition than the other, one ought to assert the sentence with the stronger presupposition. This idea is adapted from Leahy (2011), though the order of explanation is reversed.

There are certain general constraints on modal bases; not just any set of propositions, no matter how bizarre, can be the value of a modal base in a context. The version of the view that derives the meaning of the indicative via Maximize presupposition relies on two such constraints on modal bases. These are intended to be general constraints that apply both in the indicative and subjunctive case. Empty modal bases, containing no propositions, trivially satisfy both of these principles, but many nonempty modal bases do as well.

The first is that the modal bases are realistic, meaning that at each world, the propositions in the value of the modal base at that world are true at that world:

Realism. For all contexts $c$, modal bases $f$, and propositions $p$, if $p \in f\left(w_{c}\right)$ then $w_{c} \in p$.

The motivation for this principle is that if, in some context, the modal base were not realistic, then the world of the context would be inconsistent with the propositions in $f\left(w_{c}\right)$, and thus outside the worlds consistent with the modal base, $\cap f\left(w_{c}\right)$. Since

8 See Condoravdi (2001) for some discussion of this question. 
the selected worlds of the antecedent are a subset of $\cap f\left(w_{c}\right)$, they would not include the world of the context, even if the antecedent were true, and then we would face the problems to be discussed below for the views of Iatridou (2000) and Schulz (2014) in section 3.1.

The second assumption is that at every world and at every context, the propositions in the value of the modal base are among the presuppositions of the context:

Context-inclusion. For all contexts $c$, modal bases $f$, and propositions $p$, if $p \in f\left(w_{c}\right)$ then $p \in C$, where $C$ is the common ground in c.

This does not, to be clear, specify that all presuppositions of the context are in the modal base, merely that only presuppositions of the context can be in the modal base. The intuitive idea behind this principle is that there is no context $c$ and no proposition $p$ such that a conditional beginning if $p$ would be vacuously true in $c$ even though $p$ is contingent and consistent with the presuppositions in $c$. If a proposition is contingent and compatible with the presuppositions of the context, then the truth of a conditional with that proposition as its antecedent is a substantive question, depending on whether the consequent is true at the selected antecedent worlds. This principle is still consistent with propositions outside the common ground being in the ordering source. Unknown factual information can therefore still constrain the worlds at which the consequent must be true for a whole conditional to be true.

The principle of Context-inclusion may be controversial for two reasons. First, one might object that epistemic modals can be sensitive to bodies of information whose content is not known or presupposed in common by speakers in the context. It is correct that epistemic modals are sensitive to such bodies of information, but they too can be construed as part of the ordering source, consistent with Contextinclusion. This is the treatment given by Kratzer (1991). In Kratzer's treatment of epistemic modals, the modal base consists of a body of known information while the ordering source can be a body of information that is more or less reliable. Second, Context-inclusion rules out the historical modal base proposed by Condoravdi (2001), Ippolito (2006), Kaufmann (2005) and Khoo (2015), among others. A historical modal base is consistent only with worlds that are identical to the world of evaluation up until the time of evaluation, and may diverge only with respect to what is the case in the future. Clearly, in most contexts, the context set includes worlds that differ in their history up to the time of utterance from the world of the context: speakers do not have perfect information about the history of the world. Thus, a historical modal base will include some propositions not in the common ground. Context-inclusion will require this asymmetry between past and future similarity to be treated in the ordering rather than the modal base, as is done by Lewis (1979). The reasons for having historical modal bases rather than historical 
orderings are mainly internal to past-as-past views; these views require a modal base with respect to which conditionals are vacuous at the time of utterance but substantive at past times. Thus, overall, one can allow unknown facts - whether historical or informational - to affect the selection of worlds, consistently with Context-inclusion, so long as they are in the ordering source rather than the modal base. The principle of Context-inclusion is just motivated by the idea that if $p$ is consistent with the common ground, conditionals beginning if $p$ have substantive, nonvacuous truth conditions. Historical modal bases have also been proposed for the overt modal in a double-modal analysis of prioritizing conditionals, ${ }^{9}$ but as mentioned above, the interaction of such analyses with the present view awaits a separate treatment. At any rate, a prioritizing or deontic conditional is not an assertoric alternative to an ordinary single-modal "would" conditional for purposes of its interaction with Maximize Presupposition.

Thus, while these assumptions are contestable, I think they are reasonably plausible to adopt within a past-as-modal framework. These two assumptions together entail that in any context of utterance, the modal base of the context must be a subset (though not necessarily a proper subset) of the factive common ground. Any proposition that is not part of the factive common ground must either be false, in which case its inclusion in the modal base would violate Realism, or not be presupposed, in which case its inclusion in the modal vase would violate Contextinclusion.

Now suppose that in some context in which a conditional is to be asserted, the modal base is a proper subset of the factive common ground. In such a case, the conditional meets the presuppositions of the subjunctive, while the indicative carries no presupposition. The conditionals otherwise convey the same information, and thus Maximize Presupposition requires that the conditional is asserted in the subjunctive. Thus the only contexts in which the conditionals are not equivalent are ones in which the modal base is the factive common ground. In such cases only the indicative form is assertable, because the presupposition of the subjunctive is not met.

Thus, either view about the indicative produces the result that the subjunctive form of a conditional is assertable only in contexts in which the modal base is a proper subset of the factive common ground, and that the indicative form is assertable only in contexts in which the modal base is the factive common ground. Also, the syntactic thesis and the semantic explanations here are separable. Sauerland (2002), regarding just the temporal case, argues that the present tense is semantically vacuous, but its use implicates that the time in question overlaps the time of the context since if it were in the past, Maximize Presupposition would require the

9 See Condoravdi \& Lauer (2016) and Kaufmann \& Schwager (2009). 
sentence to be asserted in the past tense. Analogously, one might propose that there is syntatically a present tense in indicative conditionals, but that it is semantically vacuous. I remain neutral among all these options.

The general idea of taking the meaning of one of the forms as a presuppositional implicature from the meaning of the other is taken from Leahy (2011). Leahy, however, takes the subjunctive to carry no presupposition at all, and the indicative to presuppose that the antecedent is epistemically possible. Thus, the direction of the implicature is reversed. I do not have any decisive argument against Leahy's proposal, but it is challenging to see how it could be incorporated into a past-asmodal framework. If the subjunctive is vacuous, as Leahy proposes, it does not relate to a relation $<$ in any clear sense, as the past tense does. Indeed, it is also challenging to see how it could be incorporated into a past-as-past framework, since the temporal shift induced by the past tense in these views also gives rise to substantive presuppositions. Overall, I am sympathetic to the view of von Fintel (1998) that it should be the default hypothesis that the indicative is the unmarked form.

\section{The view in action, compared with previous views}

Let us now turn to consider the view's implications for various semantic and pragmatic points that are related to the morphological distinction. Along the way, we shall compare the view to various other previous views that give a different treatment of similar phenomena. This will illustrate the motivations for the various formal points in the view.

\subsection{Actuality: Schulz and Iatridou}

Two previous past-as-modal views are those of Iatridou (2000) and Schulz (2014). Both give past-as-modal views in the structural sense defined here, but they differ with respect to what they take the elements in the structure to be.

In the view of Iatridou, the entities on which the modally interpreted past tense operates are sets of worlds, and the designated set of worlds $i^{*}$ is the set of worlds that are epistemically possible in the context of utterance. The relation $<$ is exclusion. In subjunctive conditionals, the past tense applies to the worlds of the antecedent where the consequent must be true in order for the conditional to be true. (Let us describe these worlds as the selected antecedent worlds; this is inspired by Stalnaker (1968), but is not intended to convey that the worlds are determined specifically by a Stalnaker-style selection function rather than an ordering). Thus, the proposal is that in subjunctive conditionals, the set of worlds selected by the antecedent excludes those that are epistemically possible in the context of utterance. 
This view is vulnerable to an objection discussed in Mackay (2015). Since knowledge is factive, the world of utterance is always one of the epistemically possible worlds in a context of utterance. This means that Iatridou's proposal has the consequence that the selected worlds of the antecedent can never include the world of utterance. This means that a sentence like (6) should be true in all contexts:

(6) If Jones had taken arsenic, something would be different from how it actually is.

If the selected worlds of the antecedent exclude those that are epistemically possible, then they exclude the world of utterance. At any world other than the world of utterance, the consequent of (6) is true. Thus, by this semantics, this should be true in all contexts. But this result is not correct. A sentence like (6) is false in a context in which Jones did in fact take arsenic.

Sentence (6) is similar to one given by Anderson (1951) as an objection to the view that conditionals should be asserted only when their antecedents are counterfactual:

If Jones had taken arsenic, he would have shown just exactly those symptoms which he does, in fact, show.

Clearly, in a context in which a doctor asserts (7), it is not presupposed or asserted that the patient did not take arsenic. This is not an objection to Iatridou's view, however. Her view allows subjunctives to have antecedents that are true or presupposed to be true. Even if the selected worlds of the antecedent exclude the world of utterance, they may still be worlds at which an antecedent and consequent true at the world of utterance are true.

The view of Schulz (2014) is similar, though it differs in various technical details. ${ }^{10}$ The most important difference between Schulz's view and Iatridou's is that the set of worlds excluded by the past tense's modal reading is not determined by a factive attitude. Rather, the set of worlds excluded by the past tense is a set Schulz calls the epistemic center. The epistemic center, in a context, is the set of worlds consistent with speakers' expectations about how things normally go. Since speakers' expectations are sometimes at odds with how things are in fact, the world of the context is not in the epistemic center in all contexts. This allows that a sentence like (6) can be false in some contexts. In a context in which the world of the context

10 Rather than the three-part structures described here with which tense interacts, Schulz gives her view in terms of five-part structures in which a set of times and a set of intervals are each a part of the structure, as is a subinterval relation $\subseteq$, and in the modal case both a set of worlds and a set of sets of worlds, as well as a subset relation. I have not made this explicit in my presentation, since I assume that the subset relation is defined in the standard way. 
is outside the epistemic center, the world of the context might be among the selected worlds even as the selected worlds exclude the epistemic center. If so, then if Jones did take arsenic, the antecedent of (6) is true at one of the selected worlds and its consequent is false, allowing the conditional to be false where the antecedent is true.

However, as Mackay argues, this does not really solve the problem. The intuitive prediction is that if Jones did indeed take arsenic, then (6) is false regardless of whether everything is conforming to speakers' expectations. What sentences like (6) show is that when the antecedent of a subjunctive conditional is true, the world of the context should be among the selected worlds in all contexts, regardless of whether the world conforms to speakers' beliefs or expectations. This is the principle of centering, which both Lewis and Stalnaker uphold on logical grounds, to validate modus ponens for subjunctives. Indeed, they both uphold a stronger principle, that of strong centering, which is that the world of the context is always the sole selected world for a conditional with a true antecedent. I am neutral here on whether centering is strong or weak, but a theory of subjunctive conditionals should not rule it out altogether. It should be a constraint on past-as-modal views that they allow the world of the context to be at least among the worlds selected, if not the only world selected, for subjunctives with true antecedents.

This problem also illustrates why we should not adopt what might seem, at first glance, to be the past-as-modal view in which the analogy between tense and traditional views of subjunctive conditionals would be most straightforward: the view that in the schema $\left\langle, I,<, i^{*}\right\rangle$, the indices $I$ are possible worlds, $i^{*}$ is the actual world, and the relation $<$ is the relation of comparative distance from the actual world in the similarity ordering, such that for all worlds $w_{1}$ and $w_{2}, w_{1}<w_{2}$ iff $w_{1}$ is more remote from the actual world than $w_{2} .{ }^{11}$ The resulting view would maintain that the worlds of the antecedent in the case of a subjunctive conditional bear the relation $<$ to the actual world. The problem with this view is that since the actual world is not more remote from itself than itself, the actual world could not be among the selected worlds for a subjunctive conditional. And then the problem just discussed would arise. This problem would be avoided if we replaced this understanding of $<$ with $\leq$, the relation of being at least as far from the actual world as another world. But if the designated index $i^{*}$ is the actual world in a context, then bearing the relation $\leq$ to $i^{*}$ is (given centering) a trivial condition: all worlds are at least as remote from the actual world as the actual world. No matter which worlds are selected for the evaluation of indicative conditionals, they cannot fail this condition, and so postulating that the selected worlds in subjunctive conditionals satisfy it does not

11 This notation reverses the conventional order from Lewis (1973) and Kratzer (1981), in which ' $w_{1}<w_{2}$ ' means that $w_{2}$ is more remote than $w_{1}$. This is in order to harmonize the notation with the convention in tense, in which ' $t_{1}<t_{2}$ ' means that $t_{1}$ precedes $t_{2}$, and is thus more remote from the present in the past direction. 
distinguish indicative from subjunctive conditionals. A viable past-as-modal view requires the relation $<$ to which the past is sensitive to be distinct from the ordering that selects the nearest possible worlds.

In contrast with Iatridou's view, mine predicts that the world of utterance can be among the selected worlds for a subjunctive. Suppose that in some context $c$, the modal base is a proper subset of the factive common ground; thus, the conditional should be asserted in the subjunctive. Since the factive common ground contains only propositions true at the world of the context, so too does any proper subset of the factive common ground. The world of the context is therefore among the worlds consistent with the modal base. Assuming a centered ordering, the world of the context will therefore be among the selected worlds if a conditional uttered in $c$ has a true antecedent.

So for example, suppose for some context $c$ that Jones took arsenic at $w_{c}$, and suppose that the problematic example, here repeated as (8), is uttered in $c$.

(8) If Jones had taken arsenic, something would be different from how it actually is.

The past tense expresses a presupposition that the modal base is a proper subset of the factive common ground. Since the proposition that Jones took arsenic is true, it must be consistent with the factive common ground. It is therefore consistent with any proper subset of the factive common ground, and therefore with any candidate modal base that satisfies the relevant presupposition. If the ordering is centered, then $w_{c}$ is among the selected worlds, and the consequent is false at $w_{c}$. Thus the conditional is false, which is the correct prediction.

Consider also the Anderson case, here repeated as (9):

(9) If Jones had taken arsenic, he would have shown just exactly those symptoms which he does, in fact, show.

Here the reasoning is similar. As we have just shown, nothing in the view prohibits a subjunctive conditional from having the world of the context among the worlds of the antecedent selected. The world of the context can only be among the selected antecedent worlds if the antecedent is true at the world of the context. Therefore, nothing about the use of a subjunctive requires that the antecedent be false.

\subsection{Factivity: Stalnaker and von Fintel}

Another element of the view is that the designated modal base which plays the structural role of the present time is the factive common ground rather than the 
whole common ground. To motivate this choice, it will he helpful to compare the view with those of Stalnaker (1975) and von Fintel (1998).

The tradition of locating the difference between indicative and subjunctive conditionals in their relation to the presuppositions of the context begins with Stalnaker (1975). The central formal object in Stalnaker's system is the context set, which is the set of worlds consistent with the common ground, not the set consistent with the factive common ground. Nevertheless, in Stalnaker's view, it is not the case that the selected worlds for indicatives are always within the context set. Nor is it his view that indicative conditionals presuppose that the selected worlds are within the context set. Indicative conditionals can have selected worlds outside the context set and still be defined, without presupposition failure. This situation can arise when the presuppositions of the context are not all true. This is due to the conditional structure of Stalnaker's constraint on selection functions.

Stalnaker's theory involves a truth condition and a constraint on selection functions. Stalnaker's semantic apparatus involves, in addition to the standard model structure for modal language, a selection function $f$ with a domain of propositionworld pairs and a range of worlds. Intuitively, for any world $w$ and proposition $p$, the value of $f(p, w)$ is the nearest world to $w$ at which $p$ is true. The conditional if $p, q$ is true at a world $w$ if and only if $q$ is true at $f(p, w)$. The selection function, meanwhile, is subject to the following constraint:

If the conditional is being evaluated at a world in the context set, then the world selected must, if possible, be within the context set as well (where $C$ is the context set, if $w \in C$, then $f(p, w) \in C) .^{12}$

Although this constraint is a general pragmatic one, according to Stalnaker, the subjunctive is a signal that it is being given up, whereas it holds without exception in the indicative form. Thus, in effect, the constraint governs only the indicative form.

12 The wording in (10) is taken directly from Stalnaker (1975), aside from my having changed the variables for worlds and propositions to $w$ and $p$ to match my notation. The verbal statement, unfortunately, does not match the formal statement in parentheses. The verbal statement has two conditional antecedent clauses: "if the conditional is evaluated at a world in the context set" and then later "if possible". The formal statement, though, lacks anything corresponding to this second qualification, "if possible": it simply states that if the world of evaluation is in the context set, then so too is the selected world. I go by the formal statement here, and I am not entirely clear about the intended role of "if possible". One possible interpretation is that since (10) is intended as a general pragmatic condition, it applies in a sense even in the case of subjunctives, but one must use the subjunctive in the case that it is not possible to select a world in the context set. Thus subjunctives do not so much violate the constraint as signal that the "if possible" does not apply". But this cannot be the whole function of the subjunctive, since in Anderson's case about the patient, the subjunctive selects a world outside the context set even where it would be possible to select one inside the context set. Thanks to Magdalena Kaufmann for helpful discussion here. 
The condition stated in (10) is given in conditional form: "if the conditional is being evaluated at a world in the context set..." What is the role of this conditional antecedent? Consider an alternative view stating that indicatives are governed by the following simpler constraint:

(11) The world selected must be within the context set.

This constraint is formed just by deleting all conditional qualifications from Stalnaker's actual constraint. In the resulting view, the difference between the two conditionals is simple: with the indicative, the selected world must be within the context set, while with the subjunctive, it need not be.

Contexts in which the speakers' presuppositions are false show this view to be incorrect. The view is vulnerable to an objection mistakenly made against Stalnaker's actual view by Edgington (1995). Presupposition, in Stalnaker's apparatus, is not a factive attitude: a context can have false presuppositions. To use Edgington's example, suppose that we are in a context in which we presuppose wrongly that dancing will make it rain the next day. At such a context, at every world in the context at which we dance, it rains the next day. Suppose that (12) is asserted, the speakers dance, and it does not rain:

(12) If we dance, it will rain tomorrow.

If the world selected for an indicative is in the context set even when the world of evaluation is not, then the selected world at which the speakers dance must be one at which it does rain. But then the conditional is predicted to be true. This prediction is incorrect: in the context described, the conditional (12) is false, since the speakers danced and then it did not rain. After seeing that it did not rain, a speaker would still maintain that they had believed that if they danced, it would rain, but they would retract the claim that it was the case that if they danced, it would rain. The constraint in (11) would predict that sentence (12) would be true, while Stalnaker's own (10) allows it to be false. Thus, this conditional qualification on the constraint is crucial to allowing conditionals to be false even when they would follow from speakers' false presuppositions. This issue is discussed by Stalnaker (2005). Similar issues are pointed out by Nolan (2003).

The view of von Fintel (1998) also faces this problem. Von Fintel's overall truth conditions differ from Stalnaker's; in von Fintel's view, the conditional is a contextually restricted strict conditional, with a domain of worlds that shifts from context to context. The conditional's truth requires the truth of the consequent at all the worlds in the domain at which the antecedent is true. Within this framework, von Fintel's account of the difference between indicative and subjunctive is inspired by Stalnaker, but with certain differences; among these are the absence of the 
conditional qualification on the constraint. Indicative conditionals are governed by a default constraint that the domain of worlds from which the antecedent selects is within the context set:

$$
\mathrm{D}(\mathrm{w}) \subseteq \mathrm{C}
$$

The subjunctive conditional carries a presupposition that this constraint is lifted and the domain is partially outside the context set:

$$
\mathrm{D}(\mathrm{w}) \nsubseteq \mathrm{C}
$$

Since the selected worlds of the antecedent must be within the domain of quantification, von Fintel's constraint on indicatives entails that the worlds selected are in the context set. This is essentially the condition in (11) above, aside from the point that Stalnaker's selection function selects a single world. And so this view likewise seems to predict that (12) should be true in the context described. If the whole domain is within the context set, the selected worlds of the antecedent must be as well, and so the conditional should be true. But this is the wrong prediction. As cases like (12) show, the antecedent may select from outside the context set for both indicative and subjunctive conditionals. We should note, furthermore, that in the context described, (12) is not unassertable or undefined; it is simply false, unbeknownst to speakers. A speaker who knows all the relevant meteorological facts will respond by simply denying the conditional; there is no intuition that the question of whether it will rain if we dance doesn't arise. Thus, although the speakers do have false presuppositions in the context described, the utterance itself does not suffer from presupposition failure as standardly understood. Thus it does not solve the problem to propose that (11) or something like it is a presupposition.

This problem is avoided when the constraint is, as in Stalnaker's original, merely that if the world of evaluation is in the context set, then the world selected is as well. For the world of evaluation to be in the context set is just for all the presuppositions of the context to be true at the world of evaluation. But in the above case, the speakers have a false presupposition. Thus, the constraint does not require that the world selected be in the context set. It is consistent with the conditional's being asserted in the indicative that the world selected should be outside the context set. ${ }^{13}$ However, if we make the designated index the factive common ground, the need for

13 Starr (2014) ascribes to Stalnaker a principle he labels "Stalnaker's Distinction", which is as follows: "An indicative conditional focuses solely on antecedent-worlds among the contextually live possibilities $c$, which represent what's being taken for granted in the discourse. A subjunctive conditional focuses on antecedent-worlds that need not be among those possibilities, that is they may be counterfactual from the perspective of the discourse." The considerations just discussed show that we should be cautious in attributing this principle to Stalnaker; there is, rightly, an important sense in which he allows indicative conditionals to pertain to worlds outside the context set. 
this conditional qualification on the constraint disappears. My view predicts, like Stalnaker's, that when speakers have false presuppositions - i.e. when the world of utterance is not in the context set - the selected worlds, even for an indicative, can be outside the context set. Suppose that speakers have false presuppositions, and so the world of the context of utterance is not consistent with the common ground. With an indicative conditional, the modal base is the factive common ground. A world can be consistent with the factive common ground while being inconsistent with the common ground as a whole. So even if the worlds of the antecedent are selected from among worlds consistent with the factive common ground, they may still be outside the context set.

For example, consider again Edgington's example about the rain.

(13) If we dance tomorrow, it will rain.

In the intended context, it is presupposed that rain dances lead to rain. Thus, it is inconsistent with the common ground that the speakers will dance and it will not rain. But since this presupposition is false, it is consistent with the factive common ground that the speakers dance and it not rain. Assuming a plausible ordering, some worlds consistent with the factive common ground where speakers dance and it does not rain are nearer to the world of the context than any where the speakers dance and it does rain, and thus they will be the selected antecedent worlds. In this context, the conditional is appropriately asserted in the indicative, but the selected worlds are outside the context set.

Given that the standard temporal meanings of tenses are not in conditional form, the conditional form of Stalnaker's constraint is one of the main obstacles to absorbing his view into the past-as-modal framework. By making the past tense relate to the factive common ground rather than the common ground or context set itself, we achieve the intended effect of that conditional constraint while maintaining the structure of the past-as-modal view. Nolan (2003) argues for making the distinction around a factive state on similar grounds.

\subsection{Assertability}

A central difference between indicatives and subjunctives is that a conditional is assertable in the indicative only if its antecedent is consistent with the common ground, while subjunctive conditionals can have antecedents that are presupposed to be false. An account of conditionals should be able to explain this difference in assertability. These norms of assertability pertain to the common ground, not just to the factive common ground. One might therefore wonder if making the factive common ground the designated index undermines our ability to explain these norms of assertion. 
In fact, given the foregoing discussion, one might raise the same worry about Stalnaker's original view. The explanation of why counterfactuals must be subjunctive, in Stalnaker's view, is rendered more complex by the inclusion of the conditional antecedent on the constraint on selection functions. Suppose the constraint were just that the selected world were always in the context set. Then if the antecedent were presupposed to be false, there would be no worlds at all in the context set at which the antecedent were true. So the conditional could not be asserted in the indicative while obeying the constraint. But given that the constraint actually has a conditional antecedent limiting the restriction of selected worlds to contexts in which the world of evaluation is in the context set, why do we not need to analogously restrict the derived norm of assertion to the claim that if the world of evaluation is in the context set, then a conditional whose antecedent is false is assertable only in the subjunctive? How can a norm that binds speakers regardless of whether the presuppositions are true be derived from a principle whose application depends on whether their presuppositions are true?

Stalnaker is not completely explicit about this, but we can reconstruct an explanation using his overall theory of assertion from Stalnaker (1978). In that theory, in order for a sentence to be assertable in a context, it must be assertable at each world in the context set-not just at the single world that turns out to be the world of the context. ${ }^{14}$ The motivation for this principle is that speakers in a context generally do not know which single world is the world of utterance, and so the norms of assertion do not just require speakers to assert a proposition that is true at the single world that turns out to be their world. The norms of assertion should be tractable to speakers who do not know which specific world they are in. Now, trivially, each world in the context set is such that if it is the world of evaluation, the world of evaluation is in the context set. So if the antecedent is presupposed to be false, each world in the context set is such that at that world, the speaker must assert the conditional in the subjunctive in order to avoid violating the constraint on indicative selection functions. Thus, the conditional should be asserted in the subjunctive,

14 Stalnaker is not completely explicit about what problem obtains when an indicative conditional is uttered in violation of the constraint on indicative selection functions. Depending on how one interprets this, it affects which of Stalnaker's three principles of assertion is doing the work here. If, for example, such conditionals would fail to assert a proposition, as on some views of presupposition failure, then asserting them would violate the rule that an assertive utterance must assert a proposition relative to every world in the context set. If, by contrast, such conditionals would assert a proposition, but a different one than is normally conveyed by the indicative, then they violate the rule that an assertive utterance must assert the same proposition relative to every world in the context set. If these conditionals have some autonomous kind of assertability distinct from the kind discussed in Stalnaker (1978), then the principle that they are unassertable in a context if they are unassertable at each world in the context set is not strictly derivable from the principles of that paper, though it is very much in their spirit. 
because asserting it in the indicative would violate the constraint on indicatives at every world in the context set. This applies even if the world of the context is not, as it turns out, in the context set, since speakers have a false presupposition. In this way, a norm of assertion that applies in all contexts is derived from a constraint whose application is limited to contexts in which the world of the context is in the context set.

Similar reasoning applies in my view. Suppose in a context $c$ that some proposition $p$ is presupposed to be false. In such a context, $p$ is inconsistent with the common ground. The context set is the set of worlds consistent with the common ground. At every world in the context set, the common ground is the factive common ground: for a world to be in the context set is just for all the presuppositions of the context to be true at that world. Thus all presuppositions in the common ground are also in the factive common ground at those worlds, even if they are not in the factive common ground at the world of utterance. Thus, at each world in the context set, $p$ is inconsistent with the factive common ground. ${ }^{15}$ In order for a conditional to select any antecedent worlds at all, its antecedent must be consistent with the modal base. Thus, for any conditional with antecedent $p$ to be nonvacuous at any world in the context set, the modal base cannot be the factive common ground. So at each world in the context set, the conditional with antecedent $p$ will be unassertable in the indicative. This means that the conditional is unassertable in the indicative at the world of the context. ${ }^{16}$

Thus, the view predicts that a conditional is assertable in the indicative only if its antecedent is consistent with the common ground. The link between the truth conditions, which involve the factive common ground, and the assertability conditions, which involve the whole common ground, is established using Stalnaker's principle that an utterance is assertable only if it is assertable throughout the context set, regardless of whether the world of utterance is in fact in the context set.

15 It is not the case, granted, at each world in the context set $w$ that $p$ will be inconsistent with the factive common ground $C^{T}$ that is assigned to the modal base variable in the world of the context of utterance. But Stalnaker's principle here is that for a sentence to be assertable in a context, it must be assertable at each world $w$ in the context as interpreted in a context at that world $w$. In other words, what must be assertable at each world in the context set is the diagonal of the sentence being asserted. It is the case at each world in the context set, if $p$ is presupposed to be false, that $p$ will be inconsistent with the factive context at that world, which is the relevant issue here.

$16 \mathrm{I}$ am assuming here that there are pragmatic reasons not to assert vacuous conditionals. To the extent there are exceptions to this, they are also plausibly exceptions to the claim that one should not assert a conditional in the indicative if its antecedent is presupposed to be false, since they involve wildly false antecedents and consequents used in the indicative, as in "monkey's uncle" conditionals. 


\subsection{Presuppositions in the modal base: Heim and Kaufmann}

My view allows subjunctive modal bases to be empty, as Kratzer proposes, but it also allows them to be nonempty. If they are nonempty, though, the propositions in them at a world must still be among the presuppositions of the context. Propositions not presupposed cannot be in the modal base, though they can be in the ordering source. Why should we restrict these modal bases to presuppositions in this way? One reason has to do with the interaction with indicative conditionals just discussed; we are implementing Stalnaker's idea that the subjunctive is a device for suspending presuppositions. Another reason, though, has to do with the projection of presuppositions in subjunctives.

Heim (1992) observes two empirical points about presuppositions in the antecedents of subjunctive conditionals. One is that the antecedent can carry nontrivial presuppositions. The other is that the antecedent's presuppositions project to the global context. These points are illustrated by (14) and (15), adapted from Heim.

(14) Mary attended. If John had attended too, she would have seen him.

(15) Nobody attended. \#If John had attended too, she would have seen him.

In (14), the presupposition trigger 'too' is licensed. In (15), however, it is infelicitous, because it has just been asserted that nobody attended.

These points together entail that the local context for the antecedent is a potentially nonempty subset of the common ground. If the antecedent's local context were always empty, then the conditional in (14) would not be licensed, because its presuppositions would not be satisfied in its local context. If the antecedent's local context contained propositions outside the common ground, then the antecedent's presuppositions could contradict its local context without contradicting the common ground, and thus the antecedent's presuppositions would not project. In that case, the infelicity of (15) would not be predicted.

Heim suggests that the first of these points is problematic for Kratzer's view that the modal base in subjunctive conditionals is empty. Where $\phi$ is the antecedent and (36) is her rule for updating the contexts in indicative conditionals, she writes:

But what should we use instead of $c$ in (36) to apply the CCP of $\phi$ to? Most discussions of counterfactuals in the literature suggest that it should just be W, i.e., a context devoid of information ... But then we have an unwelcome prediction: counterfactuals whose antecedents have presuppositions should never be interpretable, because the modal base, being $\mathrm{W}$, can't have the required entailments. ${ }^{17}$

17 Heim (1992), p. 204. 
In a footnote to this excerpt, Heim cites Kratzer's view that the modal base is empty as an example of the view that the context to which the antecedent is added is devoid of information.

Heim seems to be assuming here that the modal base in Kratzer's framework also serves as the local context with respect to which the antecedent's presuppositions are evaluated. It is not completely obvious that this is a commitment of Kratzer's, since Kratzer's subject is conditionals' truth conditions and not their projection properties. However, an algorithm for generating local contexts from static meanings is given by Schlenker (2009). In Mackay (2018) it is demonstrated that the prediction of Schlenker's algorithm for Kratzer's semantics is indeed that the modal base is the antecedent's local context, as assumed by Heim. If this is all correct, then Heim's data show that in a static Kratzerian theory, subjunctive modal bases should be subsets of the global context. The modal base for a subjunctive conditional should consist only of presuppositions from the global context because it serves as the antecedent's local context, and the antecedent's local context can consist only of presuppositions from the global context.

This is a difference between my view and that of Kaufmann (2013). Kaufmann also proposes that the modal base for subjunctive conditionals consists of a subset of a contextually salient set of propositions. His view therefore shares some structural similarities with mine. Kaufmann's formal architecture is distinct from Kratzer's in that the modal base may assign a non-empty set of causally relevant propositions.

In Kaufmann's view, the set of which subjunctive modal bases are a subset is the set of "causally relevant propositions". His aim is to reconcile a possible worlds semantics for conditionals with the theory of causal modelling of Pearl (2009). However, the set of causally relevant propositions will presumably not all be in the common ground at a context. This means that propositions, for Kaufmann, can be in the modal base without being in the antecedent's local context. This suggests that Kaufmann's view requires an alternative account of the relationship between modal bases and local contexts from that suggested by Heim and confirmed in Schlenker's algorithm.

These considerations are not decisive, since the relationship between modal bases and local contexts remains an active topic of research. But I do think that these considerations provide some additional reason for restricting modal bases to presuppositions.

\subsection{The second past layer}

Some subjunctive conditionals take a second past layer, and take a pluperfect form. These are sometimes known as "two-past" subjunctive conditionals in the literature. This topic has been more extensively examined in the past-as-past literature, includ- 
ing the work of Ogihara (2000), Arregui (2009), Ippolito (2006), Ippolito (2013), Romero (2014), and Khoo (2015).

I cannot hope to do justice here to all the details of these views. My aim in the present subsection is merely to give a general sketch of which points can be imported from the past-as-past literature and which questions are unique to the past-as-modal framework. But there remains considerable future work to be done identifying exactly which insights developed in that literature can be adapted into the present past-as-modal view.

Three types of data are particularly relevant. The first is that this second layer can appear on the antecedent or consequent separately. Consider:

If Hillary Clinton had won the election in 2016, she would be president today.

In (16), there appear to be two layers of past on the antecedent and one in the consequent.

The second is that when the event or state described by a clause is in the past, the two-past form is mandatory. Analogous data are discussed by Ippolito (2013) and Romero (2014), among others.

(17) If Hillary Clinton had won the election in 2016, she would have been president last week.

(18) *If Hillary Clinton had won the election in 2016, she would be president last week.

(18) is ungrammatical due to the tense of its consequent not corresponding to the time being described.

The third, discussed by Ogihara (2000), Arregui (2009) and Ippolito (2013), is that the two-past form can appear even when the event times are non-past. Ippolito, for example, draws our attention to examples (19) and (20):

(19) If John ran the Boston marathon next spring, he would win.

(20) If John had run the Boston marathon next spring, he would have won.

Not only is (20) grammatical and felicitous, despite the apparent mismatch between the time and the tense, but in a context in which it is presupposed that John is dead, (20) is the only felicitous one of the pair.

These data give rise to three questions. First, is this second layer also a past tense, or is it a perfect aspect? Second, does it appear in narrow scope position, on the antecedent or consequent themselves, or in wide scope position, outside the conditional? And third, does it receive a modal or a temporal interpretation? The 
first two questions here are discussed in the past-as-past literature, while the third is relevant only to the past-as-modal theorist.

The first question is contested in the past-as-past literature. In the work of Ippolito (2013), what distinguishes the two-past form from the one-past form is the presence of past tense. Arregui (2009) and Schulz (2017) give views according to which the perfect is the distinguishing element. I am sympathetic to Ippolito (2013)'s critique of Arregui's position that the difference between the one-past and two-past forms is aspectual, and I find it challenging to see how Arregui's aspectual view could be incorporated into a past-as-modal view in which, with the first past tense interpreted modally, two-past conditionals would have no temporally interpreted past tense at all. Thus, I will adopt Ippolito's suggestion that the two-past form involves two layers of past tense which appear morphologically as past perfect. This conclusion should be regarded as tentative, however. Schulz (2017) argues that her past-as-modal approach can be combined with a perfect analysis of the two-past form, and it remains an interesting question for future research whether her proposal can be combined with the past-as-modal view defended here.

Regarding the second question, I also adopt the view of Ippolito that either scope position is available. This means that a "two-past" subjunctive conditionals is ambiguous between the following two forms:

$$
\begin{aligned}
& \operatorname{PAST}\left(\square_{f, o}: \text { if PAST }(p), \operatorname{PAST}(q)\right) \\
& \operatorname{PAST}\left(\operatorname{PAST}\left(\square_{f, o}: \text { if } p, q\right)\right)
\end{aligned}
$$

An argument for the availability of the narrower scope position in (21) is provided by sentences like (16), in which the past tense can appear on the antecedent and consequent separately. It is hard to make sense of (16) if both antecedent and consequent are in the scope of the same number of instances of past tense.

Regarding the third question, let us first consider the narrow scope reading exemplified by the antecedent of (16). There are two reasons for thinking that this past tense is interpreted temporally. The first is that if the modal past tense operates on modal bases, it cannot be interpreted in narrow-scope position when the antecedent and consequent do not contain a modal. The second comes from sentences (17) and (18) above, in which the two-past form is mandatory for past events. Clinton's having been president last week is no more distant from our current epistemic state than her being the president now, so it is hard to construe the differences among (16), (17), and (18) as due to a modal morpheme instead of a temporal morpheme.

In cases like (20) above, in which the two-past form does not constrain the event times of antecedent and consequent to the past, we can adopt Ippolito's view that there is a wide-scope past tense. Is this wider-scope past-tense interpreted 
temporally or modally in a case like (20)? Presumably, if the interpretation were modal, it would be that the modal base is a proper subset of a proper subset of the factive common ground. However, I do not see how this proposal would explain the difference between (19) and (20). The only proper subsets of a set that are not also proper subsets of proper subsets of it are those proper subsets that have removed only a single proposition. But we widely use one-past subjunctive conditionals with antecedents that are quite remote and clearly involve suspending multiple propositions from the common ground. Rather, the relevant point explaining the difference between (19) and (20), as Ippolito points out, appears to be that the antecedent's presupposition that John is alive was true in the past but is not true at the time of utterance.

With three plausible assumptions, we can explain the unassertability of (19) in a way broadly similar to Ippolito. The first, following Musan (1997), is that the clause "John runs the marathon next spring" presupposes that John is alive. The second, following Heim (1992), is that presuppositions project out of the antecedent of a basic one-past subjunctive conditional. The third is that when a clause $p_{t}$ has a presupposition $p^{\prime}$, the sentence $\operatorname{PAST}\left(p_{t}\right)$ presupposes that $p^{\prime}$ was true at the past time that is the assigned value of $t$ in context, but the presupposition that $p^{\prime}$ is true at the time of utterance is filtered out. The first two assumptions entail that (19) presupposes that John is still alive at the time of utterance. The third assumption therefore entails that (20) does not presuppose that John is alive at the time of utterance, but that he was alive at some salient earlier time. Thus, (19) suffers from presupposition failure. This explanation is broadly adapted from Ippolito, but in this account, unlike hers, the infelicity of (19) is due only to the presupposition projecting out of its antecedent. Even if John is presupposed to be dead, the modal bases and ordering sources are not constrained to exclude there being accessible worlds at the time of utterance at which John runs the Boston marathon next spring and wins. Thus, leaving aside its presuppositions, (19) may be nonvacuously true in the context described. But the presupposition failure is sufficient to explain its infelicity.

All these considerations favor the hypothesis that the second layer of past tense is interpreted temporally wherever it appears.

\section{Concluding thoughts}

Recall that in addition to the basic asymmetry between tense and modality, there was a tension between the optionality of the exclusion of the actual world by subjunctives and the structural constraints of the past-as-modal view, which suggest that the relation $<$ should be mandatory in the subjunctive case. As we have seen, there is an additional tension facing any view of conditionals, not really particular to past-as- 
modal views, between facts that suggest that indicatives are constrained by a factive state and others that suggest that they are constrained by speakers' presuppositions.

The reasons for thinking that indicatives interact with a factive state come from conditionals' truth conditions. We cannot presuppose our way to the truth of our conditionals: just presupposing that dancing makes it rain does not make it true in a context that if we dance, it will rain. The reasons for thinking that they interact with a purely presuppositional state, rather than a factive one, have to do with assertability conditions rather than truth conditions. An indicative conditional is assertable only if its antecedent is consistent with the presuppositions of the context. Stalnaker's view starts with indicatives being constrained by a presuppositional state rather than a factive one. To avoid truth conditions that would allow us to presuppose our way to the truth of a conditional, he complicates his constraint on indicatives with a conditional qualification. My view moves in the opposite direction. Indicatives are constrained by a factive state, and then the link between assertability and presupposition is derived from an overall pragmatic theory. The crucial insight here is found within Stalnaker's own theory of assertion: that the assertability of a sentence in a context requires its assertability throughout the context set. Throughout the context set, the common ground is the factive common ground, and therefore, if a conditional's antecedent is inconsistent with the common ground, it is inconsistent with the factive common ground. This means that at those worlds, the conditional is assertable only in the subjunctive, which in turn means that it is assertable only in the subjunctive at the world of the context.

The other tension is resolved by the way that modal bases and their restriction interact with the proper subset relation. The choice of the modal base as the subject of the past-as-modal presupposition and the proper subset relation as the $<$ relation are motivated by the need to allow subjunctive conditionals to select the world of the context with true antecedents. If the $<$ relation were exclusion, then given a factive state as the object of the relation, subjunctives would necessarily exclude the world of the context. Even with the proper subset relation playing the role of $<$, if the past operated on the selected antecedent worlds, this would still mean that the selected antecedent worlds for subjunctive conditionals always included some worlds inconsistent with the factive common ground. With a true antecedent, this is not plausible.

The selected worlds of the antecedent at which the consequent must be true in order for the whole conditional to be true are a subset of the worlds consistent with the modal base. This means that if the selected antecedent worlds are inconsistent with the factive common ground - as they must be, if the antecedent is inconsistent with the factive common ground - then the modal base must be a subset of the factive common ground. But on the other hand, the set of worlds consistent with the modal base can be a proper subset of the factive common ground without the selected 
antecedent worlds being inconsistent with the factive common ground. Thus, if the antecedent is inconsistent with the factive common ground, the presupposition of the subjunctive is always met, but if the presupposition of the subjunctive is met, the antecedent need not be inconsistent with the factive common ground. This asymmetry allows the view to predict that counterfactuals must be subjunctive while subjunctives need not be counterfactual.

We can thus show that the presence of past tense in subjunctive conditionals can be reconciled with the view that difference between the two lies in how the worlds of the antecedent relate to the presuppositions of the context rather than to the time of evaluation involved.

\section{References}

Anderson, Alan Ross. 1951. A note on subjunctive and counterfactual conditionals. Analysis 12(2). 35-38. http://dx.doi.org/10.1093/analys/12.2.35.

Arregui, Ana. 2009. On similarity in counterfactuals. Linguistics and Philosophy 32(3). 245-278. http://dx.doi.org/10.1007/s10988-009-9060-7.

Condoravdi, Cleo. 2001. Temporal interpretation of modals-modals for the present and for the past. In B. Clark D. Beaver, S. Kaufmann \& L. Casilla (eds.), The construction of meaning, Citeseer CSLI Publications.

Condoravdi, Cleo \& Sven Lauer. 2016. Anankastic conditionals are just conditionals. Semantics and Pragmatics 9(8). 1-69. http://dx.doi.org/http://dx.doi.org/10. 3765/sp.9.8.

Crouch, Richard. 1994. The temporal properties of english conditionals and modals. Tech. rep. University of Cambridge, Computer Laboratory.

Dudman, Victor H. 1984. Conditional interpretations of if-sentences. Australian Journal of Linguistics 4(2). 143-204.

Edgington, Dorothy. 1995. On conditionals. Mind 104(414). 235-329.

von Fintel, Kai. 1998. The presuppositions of subjunctive conditionals. MIT Working Papers in Linguistics 25. 29-44.

von Fintel, Kai \& Irene Heim. 2002. Lecture notes on intensional semantics. $m s$., Massachusetts Institute of Technology .

Fleischman, Suzanne. 1989. Temporal distance: A basic linguistic metaphor. Studies in Language. International Journal sponsored by the Foundation "Foundations of Language" 13(1). 1-50.

Frank, Annette. 1996. Context dependence in modal constructions: Universität Stuttgart dissertation.

Hale, Ken. 1969. Papago /cim/. International Journal of American Linguistics 25. 203-212. 
Han, Chung-hye. 1996. Comparing english and korean counterfactuals: The role of verbal morphology and lexical aspect in counterfactual interpretation. In Escol '96, 124-138. CLC Publications, Cornell University.

Heim, Irene. 1991. Artikel und definitheit. Semantik: ein internationales Handbuch der Zeitgenössischen Forschung 487-535.

Heim, Irene. 1992. Presupposition projection and the semantics of attitude verbs. Journal of semantics 9(3). 183-221.

Heim, Irene. 1994. Comments on abusch's theory of tense. In Hans Kamp (ed.), Ellipsis, tense and questions, 143-170. University of Amsterdam.

Iatridou, Sabine. 2000. The grammatical ingredients of counterfactuality. Linguistic Inquiry 31(2). 231-270. http://dx.doi.org/doi:10.1162/002438900554352.

Ippolito, Michela. 2006. Semantic composition and presupposition projection in subjunctive conditionals. Linguistics and Philosophy 29(6). 631-672. http: //dx.doi.org/10.1007/s10988-006-9006-2.

Ippolito, Michela. 2013. Subjunctive conditionals: A linguistic analysis. MIT Press. James, Deborah. 1982. Past tense and the hypothetical a cross-linguistic study. Studies in Language. International Journal sponsored by the Foundation "Foundations of Language" 6(3). 375-403.

Kaufmann, Stefan. 2005. Conditional truth and future reference. Journal of Semantics 22(3). 231-280.

Kaufmann, Stefan. 2013. Causal premise semantics. Cognitive science 37(6). 1136-1170.

Kaufmann, Stefan. 2018. The limit assumption. Forthcoming.

Kaufmann, Stefan \& Magdalena Schwager. 2009. A unified analysis of conditional imperatives. In Semantics and linguistic theory, vol. 19, 239-256.

Khoo, Justin. 2015. On indicative and subjunctive conditionals. Philosopher's Imprint 15(32).

Kratzer, Angelika. 1981. The notional category of modality. In Hans-Jürgen Eikmeyer \& Henned Rieser (eds.), Worlds, words, and contexts, 38-74. Mouton De Gruyter.

Kratzer, Angelika. 1991. Modality. In Arnim von Stechow \& Dieter Wunderlich (eds.), Semantics: An international handbook of contemporary research, 639-50. Berlin: De Gruyter.

Leahy, Brian. 2011. Presuppositions and antipresuppositions in conditionals. In Semantics and linguistic theory, vol. 21, 257-274.

Lewis, David. 1973. Counterfactuals. Malden, MA \& Oxford \& Carlton: Blackwell. Lewis, David. 1979. Counterfactual dependence and time's arrow. Noûs 455-476. Mackay, John. 2015. Actuality and fake tense in conditionals. Semantics and Pragmatics 8. 1-12.

Mackay, John. 2018. Subjunctive conditionals' local contexts. Manuscript. 
Musan, Renate. 1997. Tense, predicates, and lifetime effects. Natural language semantics 5(3). 271-301.

Nolan, Daniel. 2003. Defending a possible-worlds account of indicative conditionals. Philosophical Studies 116(3). 215-269.

Ogihara, Toshiyuki. 2000. Counterfactuals, temporal adverbs, and association with focus. In Semantics and linguistic theory, vol. 10, 115-131.

Pearl, Judea. 2009. Causality. Cambridge University Press.

Romero, Maribel. 2014. 'fake tense'in counterfactuals: A temporal remoteness approach. The Art and Craft of Semantics: A Festschrift for Irene Heim, ed. Luka Crnic \&amp; Uli Sauerland 2. 47-63.

Sauerland, Uli. 2002. The present tense is vacuous. Snippets 6(11). 12-13.

Schlenker, Philippe. 2009. Local contexts. Semantics and pragmatics 2. 3-1.

Schulz, Katrin. 2014. Fake tense in conditional sentences: a modal approach. Natural Language Semantics 22(2). 117-144. http://dx.doi.org/10.1007/s11050013-9102-0.

Schulz, Katrin. 2017. Fake perfect in x-marked conditionals. In Semantics and linguistic theory, vol. 27, 547-570.

Stalnaker, Robert. 1975. Indicative conditionals. Philosophia 5(3). 269-286. http: //dx.doi.org/10.1007/BF02379021.

Stalnaker, Robert. 2005. Conditional presuppositions and conditional assertion. In John Gajewski (ed.), Mit working papers in linguistics 51: New work on modality, Cambridge University Press.

Stalnaker, Robert C. 1968. A theory of conditionals. In Ifs, 41-55. Springer.

Stalnaker, Robert C. 1978. Assertion. In Peter Cole (ed.), Syntax and semantics 9: Pragmatics, 315-322. Academic Press.

Starr, William B. 2014. A uniform theory of conditionals. Journal of Philosophical Logic 43(6). 1019-1064.

Steele, Susan. 1975. Past and irrealis: just what does it all mean? International journal of American linguistics 41(3). 200-217.

Zvolenszky, Zsófia. 2002. Is a possible-worlds semantics of modality possible? a problem for kratzer's semantics. In Semantics and linguistic theory, vol. 12, 339-358.

John Mackay

University of Wisconsin-Madison

5167 Helen C. White Hall

600 N. Park St.

Madison, WI 53703 USA

john.mackay@wisc.edu 